INTERNATIONAL HIGHER EDUCATION - NUMBER 68 SUMMER 2012 Pages 13-14.

\title{
Challenges to Romanian Higher Education
}

\author{
Paul Serban Agachi
}

Paul Serban Agachi is president of the Academic Council, Universitatea "BabesBolyai," Cluj, Romania. E-mail: serban.agachi@ubbcluj.ro.

Romanians may be regarded as belonging to the Mediterranean culture-with relaxed values regarding time, precision, and hard work but with good characteristics in inventiveness, flexibility in approach, and adaptability to diverse environments. All these characteristics are bred on a strong heritage of the communist regime of over 50 years, a period when fake values were promoted in all fields; and lack of initiative and hidden disobedience have been encouraged to exist. This explains mainly why Romania is in this situation now.

Major changes occurred in Romania, after 1990. The market economy replaced the state-owned centralized one; the number of small- and mediumsized enterprises increased from 0 to almost 400,000 in 2010; the exports sector moved from 10 billion per year in the 1980s to 50 billion per year in 2011; and a tremendous increase in communications facilities has taken place: first place in Europe and fourth in the world, for an average speed of Internet connections.

\section{THE Higher Education Sector}

Before the 1989 Revolution, the Romanian higher education sector was restricted: 44 higher education institutions (all of them state universities or institutes), 
163,000 students (710 students per 100,000 of the population), number of $\mathrm{PhD}$ students (under $0.3 \%$ ) and number of university teachers $(11,700)$.

After 1989, the Romanian landscape of higher education changed radically: 70 brand new universities were created, and the student population increased, almost with 500 percent, until 2009. Romania really required and still needs a labor force much better skilled, than before, to reach the expectations of a more modern economy-from 5 percent labor force with a higher education degree in 1990, to 14 percent in 2010, in comparison with 26 percent in the European Union and 40 percent in the United States in 2010. The figures characterizing the higher education sector in 2009 are: 112 higher education institutions (both public and private, at parity), 1,107,362 students, 3 percent of PhD students, and 31,964 of the university teachers. The number of students per 100,000 of the population is of 5,151 in 2009, in comparison with 6,296 in the United States, 6,599 in Russia, 5,684 in Poland, or 3,525 in France. The number of students from rural areas or disadvantaged categories is at 15 percent only.

Concerning the quality of Romanian higher education, all universities have stated on their Web sites as missions: good-quality education, research at the international level, and services for society. The strategic approach is quite a new one, being introduced in 1998; and all new public and private institutions wanted mimetically to do the same thing-copying the strategic programs of the leading universities.

The competition among Romanian universities is rather a new concept, which developed under the recent circumstances of low funding, global competition, and demographic decrease. Recently, as a consequence of a new law of national education (2011), a classification in three programs at Romanian 
higher education institutions, depending mainly on the intensity of research, has been done: 12 research intensive universities, 29 universities for education and research, and 61 universities for education. The classification has the expressed intention to redistribute the budgetary allocations to the universities and to support at least two universities to become world class and in the top 500 of the rankings. There are 4 universities in Romania that can aim to the world-class category (University Alexandru Ioan Cuza Iassy, University Babeș-Bolyai Cluj, University of Bucharest, and University Politehnica Bucharest) and another 30 to 35 good-quality institutions (public and private, including those of arts).

\section{CONTEMPORARY CRISES}

The major problems with which Romanian higher education is encountered include: weak personnel qualifications because of the absence of financial motivation and of real competition (60\% of universities established after 1989 lacked appropriate legislation concerning quality assurance and also appropriate human-resource policies); teaching orientation, focused too much on accumulation, rather than solving problems; bureaucracy imposed by legislation; corruption; nepotism; lack of transparency in the university management; absence of the appropriate channels and modalities of communication inside the academic community; lack of vision and leadership at the governance of the higher education institutions; chronic underfunding; and weak elective system for leading positions in the universities. Of course, all these problems are not found in all Romanian universities, but probably at least some of them can be found in any university in Romania. 
Additionally, gross domestic product (GDP) allocated to education was at 6 percent in political statements and never exceeded 3.5 percent in reality. The allocations in research were at a peak of 0.79 percent of GDP in 2008, which created an ambition in this sector at that time. Since then, due to the economic crisis, the allocations for research decreased severely to 0.18 percent of GDP in 2009, increasing slightly after that; in education the allocation is 2.8 percent of GDP this year. What the economic crisis added to the picture in the public universities is a 25 percent decrease of the salaries of the personnel, the prohibition of employing teaching staff over three years in the public universities, and the decrease of investments close to zero. The crisis is coming on the threatening background of the decrease of demography, which will be a drop of 30 percent in 2013.

The controversial new law of education, while not being passed through the Parliament, tries to solve these problems of the education sectors by a forceful policy. The law intends to forbid wrong opinions of the legislators and does not have a stimulating spirit, curbing the university autonomy. Probably, this law will not be successful, although it will be everybody's interest to solve the problems of Romanian higher education.

\section{CONCLUSION}

Romania radically changed its political system in 1990, inducing transformations in the education sector as well. The market economy was reflected in the higher education sector, too-with higher education becoming a business as well as information technology and other services. While the private initiative formed an 
intrepid transition, brand-new universities have been opened on a background of weak legislation, regarding quality.

The most important progress is the increase in the number of students (almost 5 times) and the growth of the labor force with a tertiary degree (from under $5 \%$ to $14 \%$ ). The law of education fails to differentiate universities in categories based on their missions.

Despite these problems, the Romanian higher education system is functioning at quite normal parameters: 81 percent of the graduates are employed, compared with 82 percent in the European Union; three to four universities are classified in a number of international rankings, in the categories 600-1000. The infrastructure (buildings, teaching, and research equipment) is competitive for offering decent conditions of learning; and the international scientific contribution increased three times in recent years. 